\title{
Low expression of polypeptide GalNAc N-acetylgalactosaminyl transferase-3 in lung adenocarcinoma: impact on poor prognosis
} and early recurrence

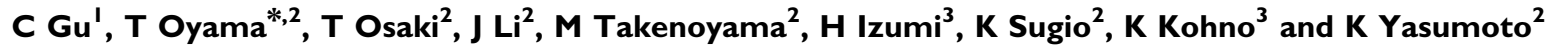 \\ 'Department of Thoracic and Cardiovascular Surgery, First Affiliated Hospital of Dalian Medical University, Dalian I I 60 I I, China; ${ }^{2}$ Department of \\ Surgery II University of Occupational and Environmental Health, School of Medicine, I-I Iseigoaka, Yahatanishi-ku Kitakyushu 807-8555, Japan; \\ ${ }^{3}$ Department of Molecular Biology, University of Occupational and Environmental Health, School of Medicine, I-I Iseigoaka, Yahatanishi-ku Kitakyushu \\ 807-8555, Japan
}

Initial glycosylation of mucin-type O-linked protein is catalysed by one of the UDP-GaINAc: polypeptide N-acetyl-galactosaminyl transferase-3 (GalNAc-T3). O-glycosylation is important in the binding of cell adhesion molecules, cell differentiation, invasion, and metastasis in tumours. This study was designed to detect GalNAc-T3 expression in lung adenocarcinoma by using immunohistochemical staining, and to evaluate the relationship between the GalNAc-T3 expression level and prognosis and recurrence in completely resected lung adenocarcinoma patients. A low expression of GalNAc-T3 was detected in the cytoplasm of tumour cells in 79 of I 48 patients (53.4\%) with lung adenocarcinoma. The low expression of GalNAc-T3 was associated with poorly differentiated tumour $(P<0.000 \mathrm{I})$, poor pathologic stage $(P<0.000 \mathrm{I})$, lymph node metastasis $(P<0.000 \mathrm{I})$, and tumour recurrence $(P=0.016)$. The lung carcinoma patients with low GalNAc-T3 expression had a poorer prognosis than those with high GalNAc-T3 expression, using both univariate and multivariate analyses (overall survival: $P<0.0001$ and $P=0.01 I$, respectively). In addition, multivariate analysis of the clinicopathological characteristics of stage I lung adenocarcinoma indicated that the low expression of GalNAc-T3 was a significant independent factor for predicting poor prognosis and early recurrence $(P=0.006, \mathrm{rr}=2.87$ and $P=0.019, r r=3.05$, respectively). The low expression of GalNAc-T3 may be a useful marker for predicting poor prognosis and early recurrence in completely resected lung carcinoma patients, particularly patients with stage I diseases.

British Journal of Cancer (2004) 90, 436-442. doi:I0.1038/sj.bjc.660 I53I www.bjcancer.com

(C) 2004 Cancer Research UK

Keywords: GalNAc-T3; lung adenocarcinoma; prognosis; recurrence

It is widely accepted that changes in the structure and distribution of cell surface glycoproteins are assumed to influence the biologic behaviour of tumour cells during malignant transformation and tumour progression (Nakamori et al, 1994). In the past few years, O-linked carbohydrate antigens, such as mucin antigen (MUC1), carcinoembryonic antigen (CEA), sialyl LewisX (SLX), CA19-9, Sialyl Tn (STn), and Tn have been reported to be associated with altered adhesion (Fogel et al, 1983; Rice and Bevilacqua, 1989), invasion (Bolscher et al, 1988; Matsushita et al, 1991; Nakamori et al, 1994), recurrence, and prognosis (Itzkowitz et al, 1990; Niklinski et al, 1992; Ogawa et al, 1994; Cao et al, 1995; Diez et al., 1996; Ohgami et al, 1999) in lung cancer and other tumours. Mucin-type O-linked carbohydrates may constitute up to $80 \%$ of the total mass of these glycoproteins (Clausen and Bennett, 1996); O-glycosylation has been shown to be important in the binding of cell adhesion molecules, cell differentiation, invasion, and

*Correspondence: T Oyama; E-mail: oyama@med.uoeh-u.ac.jp Supported in part by grant-in-aid for cancer research (No. 21457|292) from the Ministry of Education, Science, Sports and Culture, Japan. Received 26 February 2003; revised 12 August 2003; accepted 5 November 2003 metastasis in tumours (Nakamori et al, 1994; Clausen and Bennett, 1996; Sutherlin et al, 1997; Nomoto et al, 1999). Initial glycosylation of mucin-type O-linked protein was catalysed by a family of the UDP-GalNAc: polypeptide $\mathrm{N}$-acetyl-galactosaminyl transferases (GalNAc-transferase) (Hagen et al, 1993; Homa et al, 1993; Wandall et al, 1997). To date, seven distinct human GalNActransferase genes (from GalNAc-T1 to GalNAc-T7) have been cloned and characterised, and O-glycosylation is carried out in part by the differential expression of GalNAc-transferase in normal tissues and tumours (White et al, 1995; Bennett et al, 1996, 1998, 1999a, b; Wandall et al, 1997; Ten Hagen et al, 1998). Thus, the differential expression of O-linked carbohydrate antigens in tumours may be explained by the differential expression and activity of specific GalNAc-transferases.

GalNAc-T3 expression is restricted to cell lines derived from epithelial gland adenocarcinoma, but not cells derived from nonsecretory epithelial tissue carcinomas (Sutherlin et al, 1997; Nomoto et al, 1999). A recent study using a polyclonal antibody to GalNAc-T3 demonstrated that GalNAc-T3 is expressed in adenocarcinoma but not nonadenocarcinoma cell lines (Nomoto et al., 1999). Previous immunohistochemical results suggest that the anti-GalNAc-T3 antibody may be useful for diagnostic purposes in the early stages of breast cancer, but the relationship between 
GalNAc-T3 expression and prognosis and recurrence for patients with lung adenocarcinoma remains unknown.

This study was a retrospective cohort and designed to detect GalNAc-T3 expression in lung adenocarcinoma by using immunohistochemical staining, and to evaluate the relationship between GalNAc-T3 expression levels and prognosis or recurrence of the patients' tumours.

\section{MATERIALS AND METHODS}

\section{Patients and follow-up}

We examined 148 of 184 (80.4\%) consecutive patients with lung adenocarcinoma, who underwent complete surgical resection between July 1991 and September 1996 at the University of Occupational and Environmental Health, School of Medicine, Kitakyushu, Japan. The criteria for inclusion into the study were based on the availability of follow-up data. Clinicopathological data were obtained by retrospective chart review. Tumour stage was classified according to Revisions in the International System for Staging Lung Cancer (1997) (Mountain, 1997). There were 88 men and 60 women in this series, with a mean age of 64.8 years (range, $32-84$ ). None of these patients received chemotherapy or radiotherapy prior to the operation. Of $148(6.8 \%)$ patients, 10 received adjuvant chemotherapy and this adjuvant chemotherapy does not affect the prognosis of these patients.

For the postoperative follow-up, the patients were examined every month within the first year and at approximately 2- to 4month intervals thereafter. The evaluations included physical examination, chest roentgenography, analysis of blood chemistry, and carcinoembryonic antigen assay. Chest, abdominal, and brain computed tomographic scans and a bone scintiscan were performed every 6 months through the third year, and annually thereafter. If any symptoms or signs of recurrence appeared in these examinations, additional evaluations to locate the site of the recurrence were performed. Survival data were updated in April 2001. Follow-up was available for all patients, ranging from 53 to 3507 days after the primary operation (median follow-up, 48.5 months).

\section{Western blot analysis}

Cytoplasmic proteins were extracted from the frozen normal tissue and tumour tissue in adenocarcinoma patients and $5 \mu \mathrm{g}$ cytoplasmic proteins was electroblotted onto polyvinylidene difluoride membranes (Immobilon; Millipore, Bedford, MA, USA) after separation on $10 \%$ SDS-polyacrylamide gel electrophoresis gel. Polyclonal antibody against GalNAc-T3 was generated by multiple immunisations of a New Zealand white rabbit, using synthetic peptides as described previously (Nomoto et al, 1999). Immunoblot analysis was performed with a 1:5000 dilution of antiGalNAc-T3 antibody. Detection was performed using ECL (Amersham Pharmacia Biotech, Buckinghamshire, UK). High GalNAc-T3 expression breast carcinoma given by Nomoto et al (1999) was used as a positive control.

\section{Immunohistochemical staining}

A formalin-fixed, paraffin-embedded, $3-\mu \mathrm{m}$ section was obtained from each of the 148 samples of primary lesions. All specimens were stained with haematoxylin and eosin for histopathologic diagnosis. Immunohistochemical (IHC) staining was performed by a streptavidin-biotin-peroxidase complex method (Nomoto et al, 1999). Sections were immersed briefly in a citrate buffer $\left(0.01 \mathrm{molli}^{-1}\right.$ citric acid: $\mathrm{pH}$ 6.0) and incubated for two 5-min intervals at $100^{\circ} \mathrm{C}$ in a microwave oven for antigen retrieval. They were then incubated with polyclonal GalNAc-T3 antibody diluted 1:2000 for $90 \mathrm{~min}$ at room temperature by using the Labeled
Streptavidin Biotin kit (DAKO LSAB kit, CA930 13, Dako Corp., Carpinteria, CA, USA). Antibody was diluted in phosphatebuffered saline (PBS) containing $2 \%$ bovine serum albumin (BSA). High GalNAc-T3 expression breast carcinoma given by Nomoto et al (1999) was also used as a positive control.

\section{Immunostaining evaluation}

All slides were evaluated for immunostaining by three observers (CG, JL, and TO) using a blind protocol design (observers had no information on clinical outcome or other clinicopathologic data). Cells were judged positive for GalNAc-T3 when the cytoplasm or cell membranes were stained. The percentage of positive cells was calculated by counting more than 1000 cells in random high-power fields $(10 \times 40)$, and scored according to the percentage of positive GalNAc-T3 cells: score 0, $0-5 \%$; score 1, 6-25\%; score 2, 26-50\%; score 3, 51-75\%; or score 4, 76-100\% expression levels. To evaluate the correlation with clinicopathological characteristics, GalNAc-T3 expression scores were divided into two groups. Specimens with expression scores of $0-2$ were called low expression of GalNAc-T3, and specimens with scores of 3-4 were called high expression of GalNAc-T3.

\section{Statistical analysis}

The statistical significance was evaluated using the Pearson's $\chi^{2}$ test. Survival curves were plotted according to the Kaplan-Meier method (Kaplan and Meier, 1958), and differences between the curves were analysed by the log-rank test (Peto et al, 1977). The Cox proportional hazards model was applied to the multivariate survival analysis (Cox, 1972). The results of the Cox proportional hazards model did not seem to change when the follow-up was within 5 years. Data were analysed with the use of Abacus Concepts, Survival Tools for StatView (Abacus Concepts, Inc., Berkeley, CA, USA).

\section{RESULTS}

\section{Western blot analysis}

To determine the specificity of an anti-GalNAc-T3 antibody, Western blot analysis was performed in 10 cases with frozen normal tissue and tumour tissue from the same patient. GalNAcT3 expression was detected in $68 \mathrm{kDa}$ protein. High GalNAc-T3 expression breast carcinoma given by Nomoto et al (1999) was used as a positive control (lane A). Figure 1 shows the one of Western blotting analysis, in which samples were extracted from normal tissue and tumour tissue of patients with well-differentiated adenocarcinoma and poorly differentiated adenocarcinoma. GalNAc-T3 expression level of tumour tissue increased in comparison with that of normal tissue in well-differentiated adenocarcinoma, although the GalNAc-T3 expression level of tumour tissue decreased in comparison with that of normal tissue

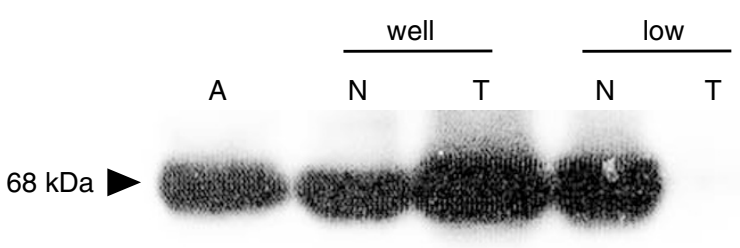

Figure I Western blotting analysis showed GalNAc-T3 expression levels of normal tissue and tumour tissue of patients with well-differentiated adenocarcinoma and poorly differentiated adenocarcinoma. Lane A; positive control (extracted from high GalNAc-T3 expression breast carcinoma), N; normal lung tissue, T; tumour tissue, well; well-differentiated adenocarcinoma, poorly; poorly differentiated adenocarcinoma. 
in poorly differentiated adenocarcinoma. The concordance rate between the results of Western blot analysis and the results of IHC detection about GalNAc-T3 expression was $80 \%$.

\section{Immunohistochemical detection of GalNAc-T3 expression in lung adenocarcinoma}

In all 148 specimens, $69(46.6 \%)$ stained positive for GalNAc-T3 in the cytoplasm of over $50 \%$ of tumour cells, and 79 (53.4\%) showed a low expression of GalNAc-T3 in the cytoplasm. In tumour cells, the GalNAc-T3 IHC staining was usually seen in the cytoplasm or cell membranes. In a few cases, immunostaining was also observed in the nucleus as well as in a chromosome in mitosis. But the surrounding normal stromal cells did not react. In normal lung tissues, GalNAc-T3 IHC staining was often seen in the respiratory epithelium and bronchial glands. Typical appearances of staining in high expression of GalNAc-T3 and low expression of GalNAc-T3 tumours are shown in Figure $2 \mathrm{a}$ and $\mathrm{b}$, respectively. The relations between GalNAc-T3 expression level and various clinicopathologic characteristics of the patients are summarised in Table 1. The frequency of low GalNAc-T3 expression was significantly lower in well-differentiated adenocarcinomas $(27.3 \%)$ than in those with moderately and poorly differentiated adenocarcinomas (51.4 and $96.7 \%$, respectively) $(P<0.01)$. Thus, GalNAc-T3 expression in tumours showed a significant relationship to histologic differentiation. As shown in Table 1, low expression of GalNAc-T3 was associated with pathologic stage (pStage) $(P<0.01)$, lymph node
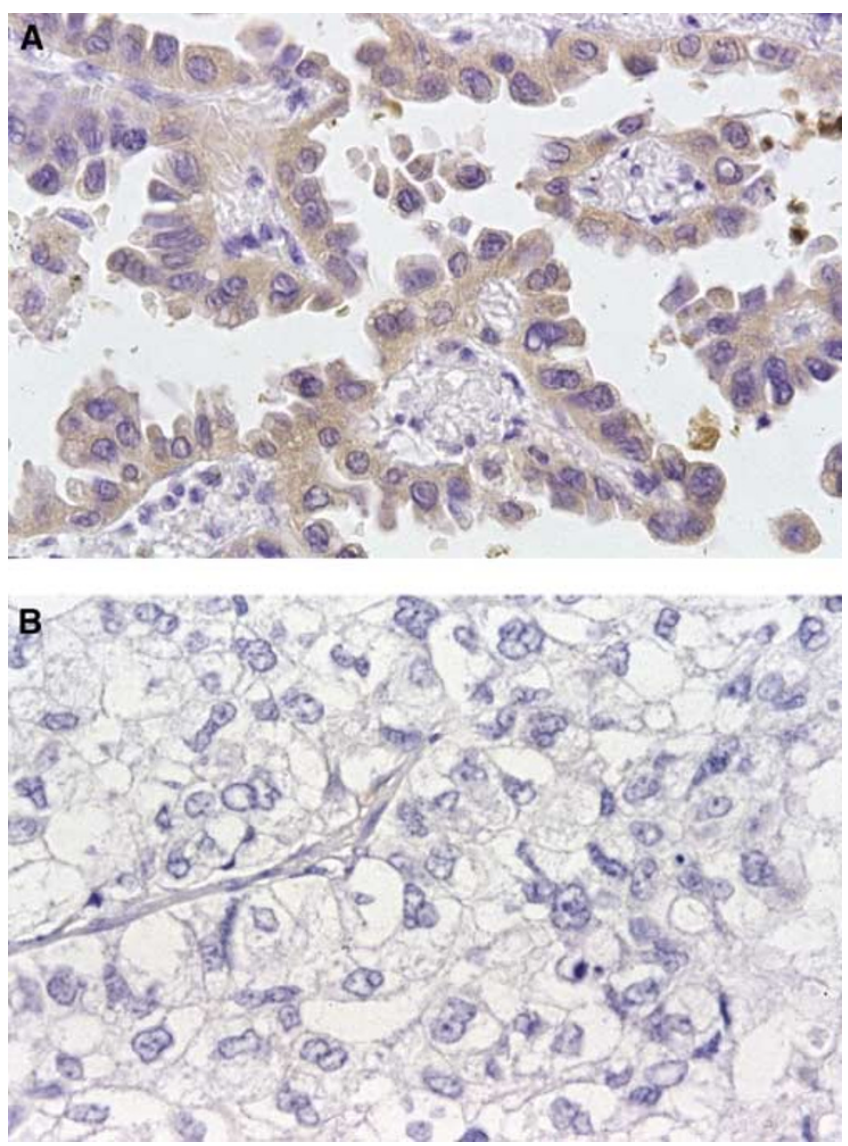

Figure 2 GalNAc-T3 $\mathrm{HC}_{\mathrm{C}}$ detection in adenocarcinoma. (A) High GalNAc-T3 expression tumour cells with deep brown stained cytoplasm are shown in the case of well-differentiated adenocarcinoma (original magnification $\times$ 400). (B) Low GalNAc-T3 expression tumour cells without stained cytoplasm are shown in the case of poorly differentiated adenocarcinoma (original magnification $\times 400$ ).
Table I Relations between the level of GalNAC-T3 expression and clinicopathologic characteristics in 148 lung adenocarcinoma

\begin{tabular}{|c|c|c|c|c|c|}
\hline \multirow[b]{2}{*}{ Characteristics } & \multirow[b]{2}{*}{ Total } & \multicolumn{4}{|c|}{ GalNAC-T3 } \\
\hline & & Low & (\%) & High & $P$ \\
\hline All cases & 148 & 79 & $(53.4)$ & 69 & \\
\hline \multicolumn{6}{|l|}{ Gender } \\
\hline Male & 88 & 54 & $(61.4)$ & 34 & \\
\hline Female & 60 & 25 & $(41.7)$ & 35 & 0.02 \\
\hline \multicolumn{6}{|l|}{ Age (years) } \\
\hline$<65$ & 68 & 42 & $(6 \mid .8)$ & 26 & \\
\hline$\geq 65$ & 80 & 37 & $(46.3)$ & 43 & 0.06 \\
\hline \multicolumn{6}{|l|}{ Histologic Grade } \\
\hline Well & 44 & 12 & $(27.3)$ & 32 & \\
\hline Moderately & 74 & 38 & $(51.4)$ & 36 & \\
\hline Poorly & 30 & 29 & $(96.7)$ & I & $<0.01$ \\
\hline \multicolumn{6}{|l|}{ Pathologic stage } \\
\hline 1 & 78 & 28 & (35.9) & 50 & \\
\hline 2 & 9 & 4 & $(44.5)$ & 5 & \\
\hline 3 & 53 & 42 & $(79.2)$ & 11 & \\
\hline 4 & 8 & 5 & $(62.5)$ & 3 & $<0.01$ \\
\hline \multicolumn{6}{|l|}{ PTNM } \\
\hline \multicolumn{6}{|l|}{$\mathrm{T}$} \\
\hline $\mathrm{TI}$ & 56 & 24 & $(42.9)$ & 32 & \\
\hline $\mathrm{T} 2$ & 51 & 26 & $(51.0)$ & 25 & \\
\hline T3 & 15 & 10 & $(66.7)$ & 5 & \\
\hline T4 & 26 & 19 & $(73.1)$ & 7 & 0.05 \\
\hline \multicolumn{6}{|l|}{ N } \\
\hline No & 91 & 33 & $(36.3)$ & 58 & \\
\hline NI & 14 & 10 & $(71.4)$ & 4 & \\
\hline N2 & 41 & 34 & $(82.9)$ & 7 & \\
\hline N3 & 2 & 2 & $(100)$ & 0 & $<0.01$ \\
\hline \multicolumn{6}{|l|}{$M$} \\
\hline MO & 140 & 74 & $(52.9)$ & 66 & \\
\hline MI & 8 & 5 & $(62.5)$ & 3 & 0.60 \\
\hline \multicolumn{6}{|l|}{ Recurrence } \\
\hline Without recurrence & 106 & 50 & $(47.2)$ & 56 & \\
\hline With recurrence & 42 & 29 & $(69.1)$ & 13 & 0.02 \\
\hline
\end{tabular}

metastasis $(P<0.01)$, and tumour recurrence $(P=0.016)$, but not distant metastasis $(P=0.60)$. A borderline significant $P$-value was also found in $\mathrm{T}$ status $(P=0.05)$.

Next, GalNAc-T3 expression level was compared to various clinicopathologic parameters of patients with stage I lung adenocarcinoma (tumours with no invasion of adjacent structures and no metastases to regional lymph nodes or distant organs). As shown in Table 2, among 78 patients with lung adnocarcinoma in stage I, a significant relationship was observed between GalNAc-T3 expression and histologic differentiation. In addition, a low expression of GalNAc-T3 was detected in 12 out of $21(57.1 \%)$ cases with recurrent disease, and this finding was statistically significant $(P=0.02)$. Of the 12 patients, 10 experienced early tumour recurrence (within 2 years of the primary operation). Finally, the pattern of recurrence seemed to be haematogenous. In all, 10 patients had haematogenous distant recurrences, one patient had a lymphogenous recurrence, and one patient had haematogenous recurrences in combination with lymphogenous metastases. Thus, the low expression of GalNAc-T3 showed a significant relationship to early tumour recurrence.

\section{Influence of GalNAc-T3 expression level on survival and recurrence}

The influence of GalNAc-T3 expression level on the patients' overall survival was evaluated. The overall 5 -year survival rate was $47.4 \%$ for the 148 patients in this study. The Kaplan-Meier survival curves demonstrated that the patients with low GalNAc-T3 expression had significantly shorter survival periods than those 
Table 2 Relations between the level of GalNAC-T3 expression and clinicopathologic characteristics in stage I adenocarcinoma

\section{GaINAC-T3}

\begin{tabular}{lccccc}
\cline { 3 - 6 } Characteristics & $\mathbf{n}$ & Low & (\%) & High & P \\
\hline All cases & 78 & 28 & $(35.9)$ & 50 & \\
Histologic grade & & & $(19.4)$ & 25 & \\
$\quad$ Well & 31 & 6 & $(36.8)$ & 24 & \\
$\quad$ Moderately & 38 & 14 & $(88.9)$ & 1 & $<0.01$ \\
$\quad \begin{array}{l}\text { Poorly } \\
\text { Pathologic stage }\end{array}$ & 9 & 8 & & & \\
$\quad$ IA & 46 & 15 & $(32.6)$ & 31 & \\
IB & 32 & 13 & $(40.6)$ & 19 & 0.47 \\
Recurrence & & & & & \\
$\quad$ Without recurrence & 57 & 16 & $(28.1)$ & 41 & \\
$\quad$ With recurrence & 21 & 12 & $(57.1)$ & 9 & 0.02 \\
\hline
\end{tabular}
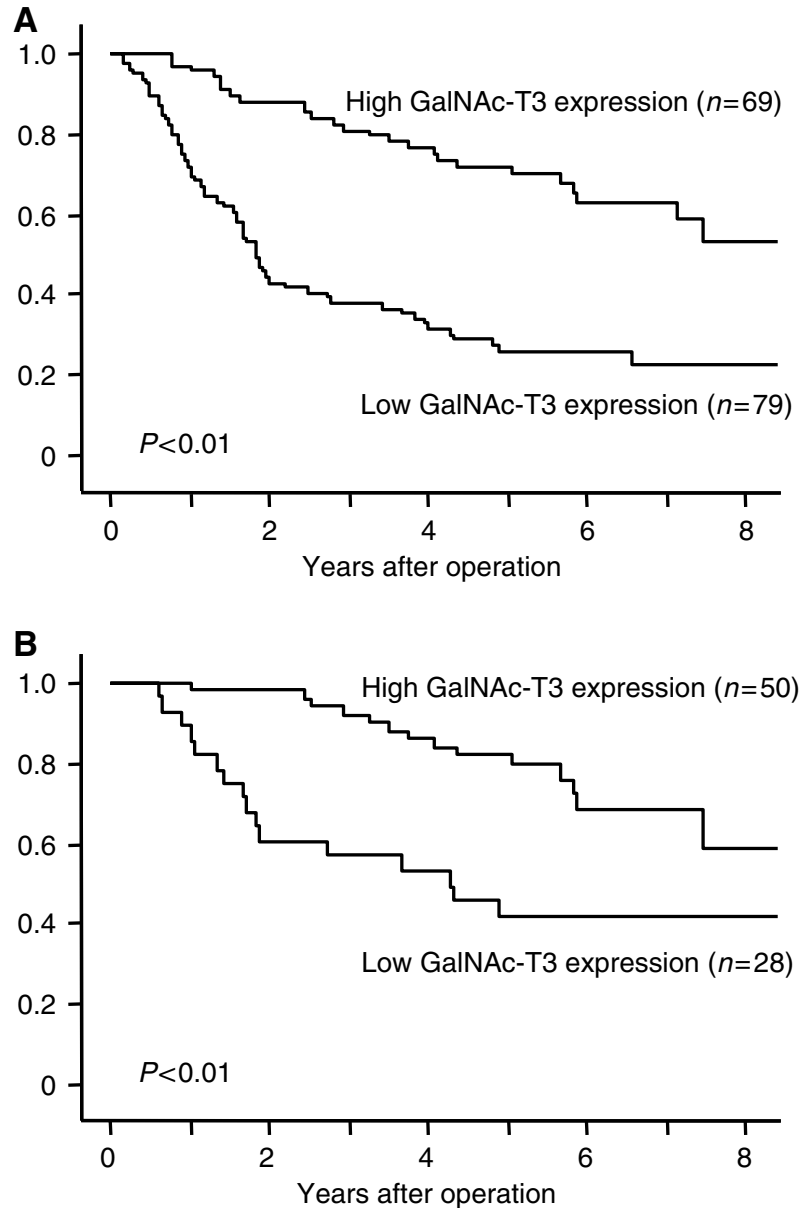

Figure 3 Survival curves of adenocarcinoma patients with low GalNAcT3 expression or high GalNAc-T3 expression. (A) Overall survival $(n=148)$, the overall 5 -year survival rates in the patients with low GalNAc-T3 expression and high GalNAc-T3 expression were 25.4 and $72.1 \%$, respectively $(P<0.01)$. (B) Survival curves of stage I lung adenocarcinoma patients $(n=78, P<0.01)$

with high GalNAc-T3 expression $(P<0.01)$ (Figure 3A). The patients with low GalNAc-T3 expression (score 0 and 1) also had significantly shorter survival periods than those with high GalNAcT3 expression (score 4$)(P<0.01$, data not shown) when the survival curves of three groups patients were determined, according to the cutoff points of 25 and $75 \%$. Among the patients with stage I $(n=78)$, the overall 5-year survival rates in the patients with low GalNAc-T3 expression and high GalNAc-T3 expression were 41.6 and $82 \%$, respectively $(P<0.01)$ (Figure $3 \mathrm{~B}$ ). In univariate analysis, six variables (gender, $\mathrm{pT}, \mathrm{pN}, \mathrm{pM}$, grade of differentiation, and high or low expression of GalNAc-T3) were found significantly to affect survival in 148 adenocarcinoma patients. Furthermore, a multivariate survival analysis demonstrated that five variables $(\mathrm{pT}, \mathrm{pN}, \mathrm{pM}$, grade of differentiation, and high or low expression of GalNAc-T3) were independently associated with patient survival (Table 3 ). The low expression of GalNAc-T3 was estimated to be associated with an increased risk of death by a factor of 2.22 in multivariate analysis $(P<0.01)$. On the other hand, in univariate analysis, three variables (pStage, grade of differentiation, and high or low expression of GalNAc-T3) were found to affect significantly survival in 78 patients with stage I adenocarcinoma. Furthermore, a multivariate survival analysis demonstrated that two variables (grade of differentiation, and high or low expression of GalNAc-T3) were independently associated with patient survival and low expression of GalNAc-T3 was estimated to be associated with an increased risk of death by a factor of 2.99 in multivariate analysis $(P<0.01$; data not shown).

To investigate whether GalNAc-T3 expression level is significantly correlated with recurrence in early-stage diseases, diseasefree survival curves of the patients with GalNAc-T3 expression in stage I were analysed using the Kaplan-Meier method. As shown in Figure 4, the patients with low GalNAc-T3 expression had significantly shorter disease-free survival periods than those with high GalNAc-T3 expression $(P<0.01)$. In univariate analysis, two variables (grade of differentiation and high or low expression of GalNAc-T3) were found to affect significantly disease-free survival in 78 patients with stage I adenocarcinoma. The variable of pStage was estimated as a borderline association $(P=0.06)$. A multivariate diseade-free survival analysis demonstrated that the variable of grade of high or low expression of GalNAc-T3 was independently associated with disease-free survival. The low expression of

Table 3 Univariate and multivariate analyses using a proportional hazard model for survival of I 48 lung adenocarcinoma patients

\begin{tabular}{|c|c|c|c|c|c|c|c|}
\hline \multirow[b]{2}{*}{ Variable } & \multirow[b]{2}{*}{$n$} & \multicolumn{3}{|c|}{ Univariate analysis } & \multicolumn{3}{|c|}{ Multivariate analysis } \\
\hline & & $95 \% \mathrm{Cl}$ & HR & $P$ & $95 \% \mathrm{Cl}$ & HR & $P$ \\
\hline \multicolumn{8}{|l|}{ Gender } \\
\hline Female & 60 & & I & & & I & \\
\hline Male & 88 & $1.02-2.54$ & 1.61 & 0.04 & $0.7 \mid-1.85$ & 1.15 & 0.58 \\
\hline \multicolumn{8}{|c|}{ 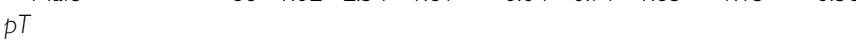 } \\
\hline $\mathrm{TI}$ & 56 & & I & & & I & \\
\hline $\mathrm{T} 2$ & 51 & $1.39-4.45$ & 2.49 & $<0.01$ & $1.28-4.38$ & 2.37 & $<0.01$ \\
\hline T3 & 15 & $1.96-8.52$ & 4.09 & $<0.01$ & $1.06-5.37$ & 2.38 & 0.04 \\
\hline T4 & 26 & $3.54-12.5$ & 6.66 & $<0.01$ & $2.16-8.72$ & 4.34 & $<0.01$ \\
\hline \multicolumn{8}{|c|}{ 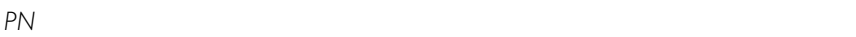 } \\
\hline No & 91 & & । & & & 1 & \\
\hline $\mathrm{NI}$ & 14 & $1.86-6.94$ & 3.59 & $<0.01$ & $0.76-3.18$ & 1.55 & 0.23 \\
\hline N2 & 41 & $2.31-5.98$ & 3.71 & $<0.01$ & $1.05-3.20$ & 1.83 & 0.03 \\
\hline N3 & 2 & $1.23-21.7$ & 5.17 & 0.03 & $2.46-59.1$ & 12.1 & $<0.01$ \\
\hline \multicolumn{8}{|c|}{ (1) - } \\
\hline MO & 140 & & । & & & 1 & \\
\hline MI & 8 & $1.85-9.26$ & 4.13 & $<0.01$ & $0.93-5.18$ & 2.19 & 0.07 \\
\hline \multicolumn{8}{|c|}{ 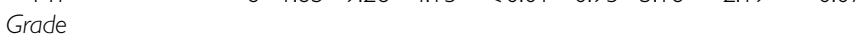 } \\
\hline Well & 44 & & । & & & I & \\
\hline Moderately & 74 & $2.09-7.66$ & 4.00 & $<0.01$ & $1.46-6.07$ & 2.98 & $<0.01$ \\
\hline Poorly & 30 & $2.11-9.37$ & 4.44 & $<0.01$ & $0.74-3.88$ & 1.69 & 0.22 \\
\hline \multicolumn{8}{|l|}{ GalNAC-T3 } \\
\hline High expression & 69 & & I & & & I & \\
\hline Low expression & 79 & $2.20-5.65$ & 3.53 & $<0.01$ & $|.26-3.9|$ & 2.22 & $<0.01$ \\
\hline
\end{tabular}

HR-hazard ratio. 
440

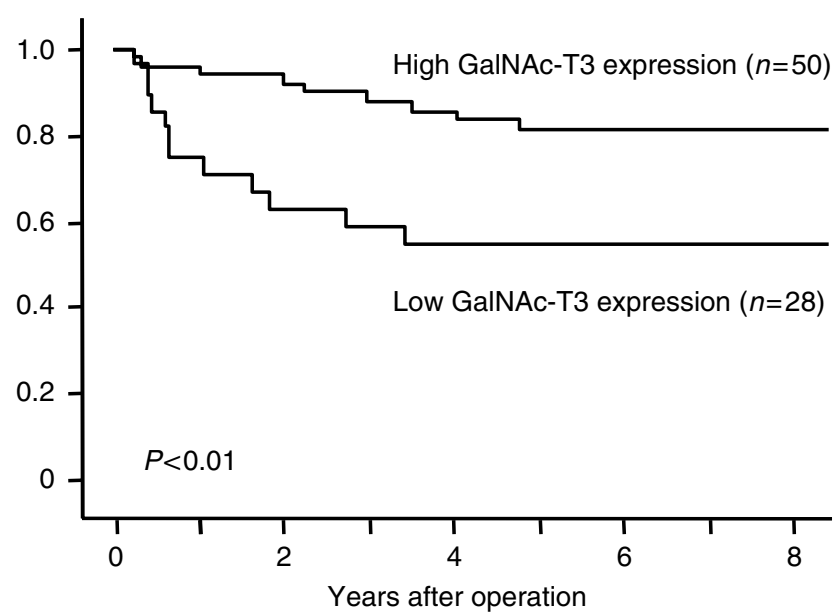

Figure 4 Disease-free survival curves of stage I lung adenocarcinoma patients with low GalNAc-T3 expression or high GalNAc-T3 expression $(n=78)$. The disease-free 3-year survival rates in the patients with low GalNAc-T3 expression and high GalNAc-T3 expression were 59 and $87.9 \%$, respectively $(P<0.01)$

Table 4 Univariate and multivariate analyses using a proportional hazard model for disease-free survival of 78 patients with stage I adenocarcinoma

\begin{tabular}{|c|c|c|c|c|c|c|c|}
\hline \multirow[b]{2}{*}{ Variable } & \multirow[b]{2}{*}{$\mathbf{n}$} & \multicolumn{3}{|c|}{ Univariate analysis } & \multicolumn{3}{|c|}{ Multivariate analysis } \\
\hline & & $95 \% \mathrm{Cl}$ & HR & $P$ & $95 \% \mathrm{Cl}$ & HR & $P$ \\
\hline \multicolumn{8}{|l|}{ pStage } \\
\hline $\mid A$ & 46 & & I & & & 1 & \\
\hline IB & 32 & $0.96-5.43$ & 2.29 & 0.06 & $0.83-5.01$ & 2.04 & 0.12 \\
\hline \multicolumn{8}{|l|}{ Grade } \\
\hline Well & 31 & & I & & & I & \\
\hline Moderately & 38 & $1.12-10.3$ & 3.40 & 0.03 & $0.87-8.39$ & 2.70 & 0.09 \\
\hline Poorly & 9 & $0.79-16.0$ & 3.56 & 0.10 & $0.25-6.60$ & 1.29 & 0.76 \\
\hline \multicolumn{8}{|l|}{ GalNAC-T3 } \\
\hline High expression & 50 & & I & & & 1 & \\
\hline Low expression & 28 & $1.38-7.86$ & 3.29 & $<0.01$ & $1.22-7.65$ & 3.05 & 0.02 \\
\hline
\end{tabular}

$H R=$ hazard ratio.

GalNAc-T3 was estimated to be associated with an increased risk of death by a factor of 3.05 in multivariate analysis $(P=0.02)$ (Table 4).

\section{DISCUSSION}

Lung cancer is the leading cause of cancer-related deaths in North America, and it became the most common cause of cancer-related deaths among Japanese in 1998 (Ginsberg et al, 1997; Hara et al, 2000). Of the four main histologic types of lung cancer, adenocarcinoma is the most commonly occurring type in Japan (Hara et al, 2000). Lung cancer is also an aggressive carcinoma with a poor outcome, and the overall 5-year survival rate is about $20 \%$ (Landis et al, 1998; Hara et al, 2000). Therefore, it is important to evaluate the malignant potential of tumour cells for a more precise evaluation of the prognosis for patients with lung adenocarcinoma.

The current study investigated the associations between GalNAc-T3 expression level and various clinicopathologic characteristics of patients with lung adenocarcinoma. The low expression of GalNAc-T3 was associated with poorly differentiated tumour, poorly pathologic stage, lymph node metastasis and tumour recurrence. Both univariate and multivariate analyses demonstrated that, among the clinicopathologic factors examined, low expression of GalNAc-T3 was a significant independent factor for predicting poor prognosis and early recurrence.

Concerning the differentiation status of lung adenocarcinoma and GalNAc-T3 expression levels, low expression levels of GalNAcT3 correlated with poorly differentiated adenocarcinoma and high expression levels of GalNAc-T3 correlated with well-differentiated adenocarcinoma. These findings are consistent with the report by Sutherlin et al (1997) that GalNAc-T3 expression is higher in welldifferentiated pancreatic adenocarcinoma cell lines. Generally, poorly differentiated adenocarcinoma are thought to have a greater malignant potential than well-differentiated adenocarcinoma. Thus, GalNAc-T3 expression level may be a marker of malignant potential in lung adenocarcinoma.

It is well known that the metastatic process consists of several stages: tumour cell escape from primary tumour, invasion of the vessels, migration, adhesion to the vascular endothelium, extravasation, and colonisation, all of which are essential for the development of clinically overt metastases. Among O-linked carbohydrate antigens, sialyl LewisX has been reported to function as a ligand of the endothelial cell adhesion molecule E-selectin (ELAM-1), which adheres human cancer cells to the vascular endothelium (Phillips et al, 1990; Walz et al, 1990; Takada et al, 1993). In addition, a mucin antigen such as MUC1 inhibits the Ecadherin-mediated cell-cell adhesion, which implies that MUC1 mucin enables adenocarcinoma cells to be detached readily from the primary tumour tissue (Wesseling et al, 1996). MUC1 polypeptide is also associated with cell surface O-linked glycoproteins such as sialyl LewisX and sialyl LewisA (Ho et al, 1995). The initial glycosylation of mucin-type O-linked carbohydrate antigens is regulated in part by the differential expression of GalNActransferase, which add GalNAc to fibronectine (Bennett et al. 1999b) and may affect the density or positions of attachment of Olinked oligosaccharides (Sutherlin et al, 1997). Differential expression of GalNAc-transferase may have a 'valvular' function in regulating $\mathrm{O}$-glycosylation in mucin-type O-linked carbohydrate antigens such as sialyl LewisX and MUC1 (Wandall et al, 1997; von Mensdorff-Pouilly et al, 2000). Therefore, GalNAc-transferase expression may play a role in tumour cell escape from primary tumour, adhesion to the vascular endothelium, and extravasation during the metastatic process.

In lung cancer, even after a 'curative' resection for pathologic stage I disease, about $30 \%$ of patients experience recurrence and eventually die of the disease (Little et al, 1986; Ginsberg et al, 1997). This suggests that occult metastases are present at the time of surgical intervention. Previous studies (Gu et al 2002) showed that micrometastatic tumour cells (cytokeratin positive cells) were present in pathologic negative lymph nodes in $34.7 \%$ of stage I non-small-cell lung cancer (NSCLC) patients after complete resectioning, and patients with micrometastatic tumour cells had a poor prognosis and a high rate of recurrent disease. To see whether GalNAc-T3 expression correlates with micrometastases, micrometastatic tumour cells were detected in a total of 1436 hilar and mediastinal pathologic negative lymph nodes from 65 patients with stage I lung adenocarcinoma, using the method previously described ( $\mathrm{Gu}$ et al, 2002), Of 65 patients, 19 exhibited lymph nodal micrometastasis, and a low expression of GalNAc-T3 was found in 12 patients $(63.2 \%)(P=0.003)$. Furthermore, this may be a partial explanation for the relationship between aberrant expression of GalNAc-T3 and early metastasis (unpublished data, with subjects different from those of this study). In the current study, among 12 out of 78 patients with low GalNAc-T3 expression and recurrent diseases in stage I lung adenocarcinoma, tumour recurrence within 2 years of the primary operation was found in 10 patients. The pattern of recurrence seemed to be haematogenous, and a low expression of GalNAc-T3 was associated with poor prognosis and early recurrence. Based on these results, it is 
reasonable to argue that a low expression of GalNAc-T3 may be a useful indicator of early tumour recurrence in stage I lung adenocarcinoma.

In conclusion, low expression of GalNAc-T3 may be a useful marker in predicting poor prognosis and early recurrence, not only in all completely resected patients with adenocarcinoma of the lung but also in those with stage I diseases. These patients need to be followed up carefully after surgery. At present, postoperative adjuvant chemotherapy is not a routine standard therapy for completely resected NSCLC patients, because it has not been shown to improve patient outcomes consistently. However, by assessing the GalNAc-T3 expression level, it would be possible to select patients who might benefit most from adjuvant chemotherapy.

\section{REFERENCES}

Bennett EP, Hassan H, Clausen H (1996) cDNA cloning and expression of a novel human UDP- $N$-acetyl-alpha-D-galactosamine. Polypeptide $\mathrm{N}$-acetylgalactosaminyltransferase, GalNAc-T3. J Biol Chem 271: $17006-$ 17012

Bennett EP, Hassan H, Mandel U, Mirgorodskaya E, Roepstorff P, Burchell J, Taylor-Papadimitriou J, Hollingsworth MA, Merkx G, van Kessel AG, Eiberg H, Steffensen R, Clausen H (1998) Cloning of a human UDP- $\mathrm{N}$-acetyl-alpha-D-galactosamine: polypeptide $\mathrm{N}$-acetylgalactosaminyltransferase that complements other GalNAc-transferases in complete O-glycosylation of the MUC1 tandem repeat. J Biol Chem 273: $30472-30481$

Bennett EP, Hassan H, Hollingsworth MA, Clausen H (1999a) A novel human UDP- $N$-acetyl-D-galactosamine: polypeptide $\mathrm{N}$-acetylgalactosaminyltransferase, GalNAc-T7, with specificity for partial GalNAcglycosylated acceptor substrates. FEES Lett 460: 226-230

Bennett EP, Hassan H, Mandel U, Hollingsworth MA, Akisawa N, Ikematsu Y, Merkx G, van Kessel AG, Olofsson S, Clausen H (1999b) Cloning and characterization of a close homologue of human UDP- $N$-acetyl- alpha-Dgalactosamine: Polypeptide $\mathrm{N}$-acetylgalactosaminyltransferase-T3, designated GalNAc-T6. Evidence for genetic but not functional redundancy. J Biol Chem 274: $25362-25370$

Bolscher JG, Schallier DC, van Rooy H, Storme GA, Smets LA (1988) Modification of cell surface carbohydrates and invasive behavior by an alky] lysophospholipid. Cancer Res 48: 977 - 982

Cao Y, Karsten UR, Liebrich W, Haensch W, Springer GF, Schlag PM (1995) Expression of Thomsen-Friedenreich-related antigens in primary and metastatic colorectal carcinomas. A reevaluation. Cancer 76: $1700-1708$

Clausen H, Bennett EP (1996) A family of UDP-GalNAc: polypeptide $\mathrm{N}$-acetylgalactosaminyl-transferases control the initiation of mucin-type O-linked glycosylation. Glycobiology 6: 635-646

Cox D (1972) Regression models and life tables. J R Stat Soc 34: 187-220

Diez M, Torres A, Maestro ML, Ortega MD, Gomez A, Pollan M, Lopez JA, Picardo A, Hernando F, Balibrea JL (1996) Prediction of survival and recurrence by serum and cytosolic levels of CEA, CA125 and SCC antigens in resectable non-small-cell lung cancer. Br J Cancer 73: $1248-1254$

Fogel M, Altevogt P, Schirrmacher V (1983) Metastatic potential severely altered by changes in tumor cell adhesiveness and cell-surface sialylation. J Exp Med 157: $371-376$

Ginsberg R, Yokes E, Raben A (1997) Non-small cell lung cancer. In Cancer, Principles and Practice of Oncology, De Vita Jr V, Helleman S, Rosenberg $S$ (eds) pp 858-911. Philadelphia: Lippencott-Raven

Gu C, Osaki T, Oyama T, Inoue M, Kodate M, Dobashi K, Oka T, Yasumoto $\mathrm{K}$ (2002) Detection of micrometastatic tumor cells in pN0 lymph nodes of patients with completely resected nonsmall cell lung cancer: impact on recurrence and survival. Ann Surg 235: 133 - 139

Hagen FK, Van Wuyckhuyse B, Tabak LA (1993) Purification, cloning, and expression of a bovine UDP-GalNAc: polypeptide $\mathrm{N}$-acetyl-galactosaminyltransferase. J Biol Chem 268: 18960-18965

Hara N, Nakanishi Y, Izumi M (2000) Epidemiology of lung cancer in Japan. Nippon Rinsho 58: 1005-1011

Ho JJ, Siddiki B, Kim YS (1995) Association of sialyl-Lewis(a) and sialylLewis(x) with MUC-1 apomucin in a pancreatic cancer cell line. Cancer Res 55: 3659-3663

Homa FL, Hollander T, Lehman DJ, Thomsen DR, Elhammer AP (1993) Isolation and expression of a cDNA clone encoding a bovine UDPGalNAc: polypeptide $N$-acetylgalactosaminyltransferase. J Biol Chem 268: $12609-12616$

Itzkowitz SH, Bloom EJ, Kokal WA, Modin G, Hakomori S, Kim YS (1990) Sialosyl-Tn. A novel mucin antigen associated with prognosis in colorectal cancer patients. Cancer 66: 1960-1966

Kaplan E, Meier P (1958) Nonparametric estimation from incomplete observations. J Am Stat Assoc 53: 457-481

Landis SH, Murray T, Bolden S, Wingo PA (1998) Cancer statistics, 1998. CA Cancer J Clin 48: 6-29

Little AG, DeMeester TR, Ferguson MK, Skinner DB, Hoffman PC, Skosey C, Blough RR, Golomb HM (1986) Modified stage I (T1N0M0, T2N0M0), non-small cell lung cancer: treatment results, recurrence patterns, and adjuvant immunotherapy. Surgery 100: 618-621

Matsushita Y, Nakamori S, Seftor EA, Hendrix MJ, Irimura T (1991) Human colon carcinoma cells with increased invasive capacity obtained by selection for sialyl-dimeric LeX antigen. Exp Cell Res 196: $20-25$

Mountain C (1997) Revisions in the International System for Staging Lung Cancer. Chest 111: $1710-1717$

Nakamori S, Ota DM, Cleary KR, Shirotani K, Irimura T (1994) MUC1 mucin expression as a marker of progression and metastasis of human colorectal carcinoma. Gastroenterology 106: 353-361

Niklinski J, Furman M, Laudanski J, Kozlowski M. (1992) Prognostic value of pretreatment CEA, SCC-Ag and CA 19-9 levels in sera of patients with non-small cell lung cancer. Eur J Cancer Prev 1: $401-416$

Nomoto M, Izumi H, Ise T, Kato K, Takano H, Nagatani G, Shibao K, Ohta R, Imamura $\mathrm{T}$, Kuwano $\mathrm{M}$, Matsuo $\mathrm{K}$, Yamada $\mathrm{Y}$, Itoh $\mathrm{H}$, Kohno K (1999) Structural basis for the regulation of UDP-Nacetyl-alpha-D-galactosamine: polypeptide $N$-acetylgalactosaminyl transferase-3 gene expression in adenocarcinoma cells. Cancer Res 59: $6214-6222$

Ogawa J, Sano A, Koide S, Shohtsu A (1994) Relation between recurrence and expression of proliferating cell nuclear antigen, sialyl LewisX, and sialyl Lewis(a) in lung cancer. J Thorac Cardiovasc Surg 108: $329-336$

Ohgami A, Tsuda T, Osaki T, Mitsudomi T, Morimoto Y, Higashi T, Yasumoto K (1999) MUC1 mucin mRNA expression in stage I lung adenocarcinoma and its association with early recurrence. Ann Thorac Surg 67: $810-814$

Peto R, Pike MC, Armitage P, Breslow NE, Cox DR, Howard SV, Mantel N, McPherson K, Peto J, Smith PG (1977) Design and analysis of randomised clinical trials requiring prolonged observation of each patient. Br J Cancer 35: 1-39

Phillips ML, Nudelman E, Gaeta FC, Perez M, Singhal AK, Hakomori S, Paulson JC (1990) ELAM-1 mediates cell adhesion by recognition of a carbohydrate ligand, sialyl-Lex. Science 250: 1130-1132

Rice GE, Bevilacqua MP (1989) An inducible endothelial cell surface glycoprotein mediates melanoma adhesion. Science 246: 1303-1306

Sutherlin ME, Nishimori I, Caffrey T, Bennett EP, Hassan H, Mandel U, Mack D, Iwamura T, Clausen H, Hollingsworth MA (1997) Expression of three UDP- $N$-acetyl-alpha-D-galactosamine: polypeptide GalNAc $\mathrm{N}$-acetylgalactosaminyl transferases in adenocarcinoma cell lines. Cancer Res 57: $4744-4748$

Takada A, Ohmori K, Yoneda T, Tsuyuoka K, Hasegawa A, Kiso M, Kannagi R (1993) Contribution of carbohydrate antigens sialyl Lewis A and sialyl Lewis $\mathrm{X}$ to adhesion of human cancer cells to vascular endothelium. Cancer Res 53: $354-361$

Ten Hagen KG, Hagen FK, Balys MM, Beres TM, Van Wuyckhuyse B, Tabak LA (1998) Cloning and expression of a novel, tissue specifically expressed member of the UDP-GalNAc:polypeptide $\mathrm{N}$-acetylgalactosaminyltransferase family. J Biol Chem 273: 27749-27754

von Mensdorff-Pouilly S, Petrakou E, Kenemans $P$, van Uffelen K, Verstraeten AA, Snijdewint FG, van Kamp GJ, Schol DJ, Reis CA, Price MR, Livingston PO, Hilgers J (2000) Reactivity of natural and induced human antibodies to MUC1 mucin with MUC1 peptides and $n$-acetylgalactosamine (GalNAc) peptides. Int J Cancer 86: $702-712$ 
Walz G, Aruffo A, Kolanus W, Bevilacqua M, Seed B (1990) Recognition by ELAM-1 of the sialyl-Lex determinant on myeloid and tumor cells. Science 250: $1132-1135$

Wandall HH, Hassan H, Mirgorodskaya E et al. (1997) Substrate specificities of three members of the human UDP- $N$-acetyl- alpha-Dgalactosamine: Polypeptide $\mathrm{N}$-acetylgalactosaminyltransferase family, GalNAc-T1, -T2, and -T3. Biol Chem 272: 23503-23514
Wesseling J, van der Valk SW, Hilkens J (1996) A mechanism for inhibition of E-cadherin-mediated cell - cell adhesion by the membrane-associated mucin episialin/MUC1. Mol Biol Cell 7: 565-577

White T, Bennett EP, Takio K, Sorensen T, Bonding N, Clausen H (1995) Purification and cDNA cloning of a human UDP- $N$-acetyl-alpha-Dgalactosamine: polypeptide $\mathrm{N}$-acetylgalactosaminyltransferase. $\mathrm{J}$ Biol Chem 270: $24156-24165$ 